2019-01-06

\title{
Identity and Charitable Giving The Six-Self Framework
}

Shang, J

http://hdl.handle.net/10026.1/13453

All content in PEARL is protected by copyright law. Author manuscripts are made available in accordance with publisher policies. Please cite only the published version using the details provided on the item record or document. In the absence of an open licence (e.g. Creative Commons), permissions for further reuse of content should be sought from the publisher or author. 


\title{
Identity and Charitable Giving
}

\author{
The Six-Self Framework
}

\author{
Jen Shang 1 \\ Plymouth Business School \\ University of Plymouth \\ Plymouth, Devon, PL4 8AA \\ Jen.shang@plymouth.ac.uk
}

ORCID: https://orcid.org/0000-0002-9166-4755

\footnotetext{
${ }^{1}$ My sincere thanks are due to Ms. Harriet Day, who proof-read the first draft of this chapter, to Prof. Americus Reed and Prof. Forehand, who gave extensive and constructive feedback to me during the editorial process, to Dr. Kathryn Carpenter, who offered her expertise on implicit and explicit category learning and her deep insights into the second draft, and to Prof. Adrian Sargeant, who thoroughly edited my second draft. This chapter cannot be made possible without you. Thank you.
} 


\section{Quick Chapter Overview}

This chapter introduces a six-element self framework that includes I/me-selves, meta-self, Not-I/me-selves and united self. Extant research illustrates how giving can be increased by about $10 \%$ by focusing on only one or two I/me-selves at a time. I will argue that more substantive uplifts may be possible by tapping into other elements of my model. I provide examples of how fundraisers can utilize the conflict management function of the meta-self, so, for example, it is possible that Mothers Against Drunk Driving can raise more money if they tap into how mothers who lost a child to a drunk driver can transition from a victim Iself to a conqueror I-self. This is a meta-self function because for quite a few months mothers may struggle to decide which I-self they should give dominion to when deciding how to live their lives (i.e. I-Self conflict management). Such a message also has the potential to help these mothers feel better faster than messages that tap into only one I-self at a time. I also give examples of how fundraisers can tap into donors' united self, whose function is to derive the most harmonious self that includes both I/me-selves and Not-I/me-selves. For example, supporters of Amnesty International may give because they care for those who human rights are abused (e.g. their loving I-self) and because they have No-tolerance for such abuse (e.g. their loving Not-I-self). The harmony the united self drives is one in which Amnesty supporters fight for as long as necessary to care for (and express their love for) the abused. United self balances the loving I-self and the loving Not-I-self. Hyper-personalizing fundraising communications under the guidance of the six-component self-framework, I argue can transform the quality of relationship that donors have with charities and the degree to which giving can transform lives. 


\begin{abstract}
Data from the Giving USA Foundation (2016) shows that individuals gave about $\$ 9.66$ billion in 2015 . This is only about $2 \%$ of GDP. It has not grown for 50 years since the record at Giving USA began. This chapter asks how a better understanding of identity relevance can be used to drive up and sustain charitable giving without detracting from how good people feel about their support. I do so by proposing a six-element self that includes the I/me-self, the meta-self, the not-I/me-self and the united self. I will explore how they shape donors' sense of who they are, how they motivate giving, how giving can shape the adaptation and development of donors' sense of self and how they together can increase psychological wellbeing (Ryff, 1995; Ryff and Singer, 2008).
\end{abstract}

Key terms: Identity, Self, meta-self, united self, charitable giving, psychological well-being 


\section{Introduction}

The United Nation's 2030 agenda was developed to solve some of the most significant social problems facing our global community today (e.g. ending poverty and hunger, producing clean water and sanitation for all, or reducing inequalities) (United Nations, 2015). Charities play a significant role in delivering some of these ambitions. The degree to which charities can succeed however is very often correlated with how successfully fundraisers can raise charitable donations. This chapter explores the possibility that identity-based motivation can contribute to the success of fundraising and hence the social missions (Reed et al, 2012; Oyserman, 2009).

Field experiments routinely show that identity relevant manipulations can increase charitable giving by a minimum of $10 \%$ when they reinforce Christian identity (Shang and Sargeant, 2018), moral identity (Shang, Reed, Sargeant, \& Carpenter, 2019) or organizational identity (Kong, 2018). At the same time, identity motivated giving is shown to change donors' sense of who they are (i.e. identity) and how they prioritize the descriptors they use to define themselves (Shang and Sargeant, 2018). Giving can also uplift and encourage people in a way that shrinks the gap between how moral they think they actually are and how moral they ideally would like to be (i.e. giving shrinks moral identity discrepancy) (Shang, et al., 2019).

These results suggest that identity and its associated identity processes (e.g. adoption, definition and redefinition, continuous adaption ${ }^{2}$ and expulsion) have the potential to change

\footnotetext{
${ }^{2}$ Adoption is defined as "the process of bringing a new identity into the self-schema", definition and redefinition is the process of assigning meaning to a new identity, continuous adaption includes four identity processes: reinforcement ("the process of strengthening an identity over time when this identity functions in a single identity maintenance system, i.e. the increase or decrease in its strength is not related to that of any other identities"), dilution
} 
giving and vice versa (Reed and Forehand, 2016). The identity relevance principle in Reed et al's 2012 theory suggests that the degree to which identity and identity processes influence giving and the degree to which giving influences identity and its processes may be partially determined by how relevant they are to each other: "When identity information is deliberatively processed, its influence will be greatest on stimuli that possess object relevance, symbolic relevance, goal relevance, action relevance or evaluation relevance to the identity" (P.316, Reed et al. 2012). My own research shows the more relevant identities and their processes are to giving, the more likely identity-motivated giving can enhance donors' psychological well-being (Shang and Sargeant, 2018).

I introduce a six-self framework that builds on Reed et al's 2012 identity-based motivation framework by differentiating six types of the self (i.e. the me-self/not-me-self, the I-self/notI-self, the meta-self and the united self) (i.e. self, Erikson, 1959; Erikson \& Erikson, 1998). It also builds on Reed and Forehand's 2016 framework by explicitly differentiating the process of self-association from self-dissociation and self-never-association, and the process of identity definition and re-definition (i.e. how people define the identities when they adopt a category label as one of their identities and how people re-define it afterwards) from other identity processes (e.g. adoption, reinforcement, dilution, elevation, suppression and expulsion). Figure 1 summarizes all the components of this framework. All regular fonts are original labels borrowed from Reed and Forehand's framework. Some definitions of these original labels are amended in light of the six-self framework. All bold fonts are new labels. I will introduce the content in this framework sequentially.

("the process of weakening an identity over time"), elevation ("the process of increasing the prominence of a given identity within a hierarchy of identities") and suppression ("the process of reducing the prominence of a given identity within a hierarchy of identities. And expulsion is defined as "the process of dispossession of an existing identity") (P. 94-95, Reed and Forehand, 2016). 
I will first define the three elements of the self that have been studied in the past (Me-Self, ISelf and Meta-Self) and what fundraisers can do with them. Then, I will explain why I think understanding the Not-Me-Self, Not-I-Self and the United Self can be useful, why the sixelements together have the potential to drive behavioural change in a way that has the highest sustainability, and why behavioural change (e.g. giving) when sustained this way, has the highest chance of maximizing donors' psychological well-being (Ryff, 1995; Ryff \& Singer, 2008).

Psychological well-being in our context is defined as donors feel 1) their donations can make a meaningful difference in their mastery of the world (competence), 2) they have made the donation decision autonomously based on what is meaningful to them, not what is meaningful to most others (autonomy), 3) their donation decision connects them to others important to them (relatedness), 4) their giving experience allows them to grow their sense of who they are (growth), 5) their giving experience allows them to clarify and move forward their purpose in life (purpose in life) and 5) they experience a sense of holistic selfacceptance of who they are through giving (self-acceptance).

I hope a better understanding of these processes by fundraisers can help reverse declines both in the donor population and the longevity of typical donor relationships. A British donor, for example, only stays supporting an organisation for 4.2 years (Sargeant, 2018) and 70\% of newly acquired American donors will not renew their support into a second year (Sargeant \& Jay, 2014).

\section{The Six-Self Framework}


Reed and colleagues (Reed et al, 2012) made an important contribution to the literature in identity and consumer behaviour by providing a parsimonious definition of identity.

"Identity is defined as any category label to which a consumer self-associates that is amenable to a clear picture of what the person in the category looks like, thinks, feels and does" (P. 310)

Examples of identities in Reed and colleagues' $(2012)^{3}$ include:

“objective membership groups (e.g., gender or family, as discussed in Epp \& Price, 2008), culturally determined membership groups (e.g., ethnicity and religion, as discussed in Dong \& Tian, 2009), abstracted role ideals (e.g., mother, friend, philanthropist), groups premised on association with a known individual (e.g., a graduate advisor), with an individual who is not known personally (e.g., Tiger Woods), or with dimensions of self that are indexed by an imagined other (Deaux, Reid, Mizrahi, \& Ethier,1995). Although there are many types of identities (as described above), it should be noted that a single identity term can bridge various classifications. For example, the term “mother" can refer simultaneously to a person's status as a member of an objective group or as an abstracted role ideal, and it is premised on an association with a known individual (i.e., the focal person's child or children)."

\footnotetext{
${ }^{3}$ For a complete list of the identities included please see Figure 3 in Reed et al (2012).
} 
Self, which is defined as self-schemas, can encompass multiple identities (Reed, 2004; Reed et al, 2012) "whether objective and relatively stable (e.g. father, son, millennial, Hispanic, etc.) or transitory and fluid (e.g. Apple user, Democrat, lawyer, athlete, etc)" P. 94 (Reed and Forehand, 2016). The solid lines around Figure 1 shows that the environment that we live in can be seen as waves of feelings, thoughts and actions that can form a range of clear pictures of category labels. The black dotted rectangular marks outline the territory traditionally included in the research of self-schemas.

\section{Me-Self and I-Self}

In order for any environmentally available category labels or definitions to enter into the traditionally defined self-schemas, they must be adopted. That is clear pictures must be unconsciously (me-self in Example (1)) or consciously (I-self in Example (2-5)) associated to the self.

\section{Me-self refers to the self/selves in which category labels are adopted unconsciously (i.e. self-associated) and processed bottom-up.}

For example, an angry mother who has just lost her child in a car accident involving a drunk driver, can look like an angry mother, think like an angry mother, feel like an angry mother and behave like an angry mother, yet never associate herself with an angry mother label or consciously define what being an angry mother means to her (Example 1 in Figure 1). This angry mother me-self can be reinforced, elevated, diluted, supressed or expulsed without any top-down process to accelerate or impede what occurs in the neuro-system bottom up (Kühnen, Hannover and Schubert, 2001). 
I-self refers to the self/selves in which category labels are adopted (i.e. self-associated) consciously and processed top-down (Voyer and Franks, 2014; McAdams, 2013).

This perspective applies when an angry mother consciously associates herself with the angry mother label and recognized that she looks, thinks, feels and behaves like an angry mother. When this self-association is consciously accepted, she can top-down define what it means. One definition could be that I have become a victim of my own anger (Example 2 in Figure 1). She can then top-down accelerate or impede any of the processes (i.e. reinforcement, elevation, dilution, suppression or expulsion) in the me-self that would otherwise occur in only a bottom-up fashion. Our me-selves and I-selves together match Reed and colleagues' definition of identity, because they both exist as self-associations with category labels. Table 1 summarizes the differences between Me-Self and I-self.

\begin{tabular}{|l|l|l|l|}
\hline & $\begin{array}{l}\text { Self-Association } \\
\text { with Category } \\
\text { Labels }\end{array}$ & $\begin{array}{l}\text { The Processing of these Category } \\
\text { Labels (i.e. reinforcement, } \\
\text { (Adoption) }\end{array}$ & Are these labels \\
and expulsion) & consciously \\
Me-Self & Unconscious & bottom-up & individual? \\
\hline I-Self & Conscious & top-down & No \\
\hline
\end{tabular}

Table 1: The Differences between Me-Self and I-Self

When some of these me-selves are top-down influenced by I-selves through shared labels (example 4 in Figure 1), definitions (example 3) or both (example 2), I-selves can top-down accelerate or impede the bottom-up processes. For example, when I-self and me-self 
(example 1) share the same definition with the same (example 2) or a different label (example 3)), I-self can top-down accelerate the elevation of the me-self. The I-self can choose to ruminate on the thoughts that "I felt angry", relive events where anger has been expressed and rehearse the association that I am a victim of my own anger (Beck, Rush, Shaw, \& Emery, 1979). This rumination can continue long after the occurrence of the trigger event and it reinforces the me-self in a way that is much stronger than what is possible with a bottom-up process alone (Andrews \& Anderson Thompson, 2009).

As another example, when I-self and me-self share only the labels but not the definitions (comparison between example 1 and 4 in Figure 1), I-self can top-down impede (not accelerate) elevation. For example, as the mother begins to feel angry and shouts at her surviving family, her I-self can step in and rehearse the thought that "I can conquer of my anger". This thought can help the person recognize that she may have failed this time, but she does not have to ruminate on the ideas or dwell in her failures. Instead, she can choose to apologize. In initiating the apology, her I-self top-down impeded the elevation that the angry me-self would otherwise receive bottom-up. When I-self and me-self share neither the labels nor the definitions (comparison between example 5 and 1), the top-down and bottom-up processes are least likely to interface with each other.

Processes like adoption, reinforcement, dilution, elevation, suppression and expulsion can occur as a combination of bottom-up and top-down processes. When only a me-self exists in isolation in the memory (i.e. they are not connected to any other me-selves or I-selves in memory, e.g. one's gambling me-self may be an isolated self that has no association to any other parts of one's life) in the self-schemas, bottom-up reinforcement and dilution determine whether a given me-self can become available in working memory to influence our looks, 
feelings, thoughts and behaviours. When multiple me-selves exist in the memory of selfschemas without any top-down influence exerted by the I-selves, bottom-up elevation and suppression processes insure that the most salient, important and relevant me-self will come into working memory (Anderson, Bothell, , Byrne, Douglass, Lebiere, \& Qin, 2004) ; Reed and Forehand, 2016). When me-selves and I-selves are connected, bottom-up and top-down processes jointly determine whether they are adopted $(+)$, reinforced $(+)$, elevated $(+)$ or diluted (-), suppressed (-) and expulsed (-). The (+) and (-) signs in Figure 1 shows whether the overall strength of association increased or decreased as a result of these processes.

\section{Meta-Self}

The Meta-self refers to the self that consciously manages the conflicts between two or more I-selves that may be in competition with each other for resources like attention, mental processing capacities or actions. (Bahl and Milne, 2010).

Figure 1 marks the territory of meta-self: all possible I-selves. As some examples, this could include one's actual self, ideal self (Higgins, 1987), moral self (Acuino and Reed), authentic self (Johnson, Robinson and Mitchell, 2004), true self (Schelegel et al, 2009; 2011), redemptive self (Guo, Klevan and MacAdamsn, 2016), extended self (Belk, 1988), collective self (Brewer and Gardner, 1996), social self (Brewer and Pierce 2005), and fused self (Swann et al 2012). Whatever label that the self chooses to consciously associate themselves with and whatever definition they choose to employ. 
The content of Meta-self is not only the two or more category associations adopted and defined by I-selves, but also how they are in conflict and the momentary hierarchies of these I-selves. By definition, we assume that people can experience only one meta-self at any given moment, although the content of the meta-self can change continuously. Meta-self does not influence me-selves unless it is through I-selves. All (+) and (-) signs as shown in Figure 1 hence can be combinations of bottom-up processes associated with me-selves and top-down processes associated with both I-selves and meta-selves.

At any given moment, the meta-self maximizes cohesion and minimizes conflicts between Iselves. In doing so, it maximizes the individual's social functions (McAdams, 2013; Bahl and Milne, 2010) and psychological well-being (Ryff1995; Ryff \& Singer, 2008). When conflicts cannot be resolved, meta-self establishes dominate I-self through the conscious elevation, suppression and expulsion of I-selves.

We will use the relationship between donors and an organization called Mothers Against Drunk Driving (MADD) to clarify what meta-self is and what function it plays. MADD's mission is to "end drunk driving, help fight drugged driving, support the victims of these violent crimes and prevent underage drinking” (MADD, n.d.). Many MADD supporters have lost their loved ones in car accident involving impaired driving. They joined MADD to reduce such deaths to zero.

A mother for example may have lost her 2-year-old son about a month ago and joined MADD immediately after that. One month after this trauma, she may consciously selfassociate with both an angry mother category label which is defined as the victim of one's anger (example 2) and a MADD mother category label which is defined as the conqueror of 
one's anger (example 5). Whenever she feels angry and is about to blow up at the smallest irritation her surviving 5-year daughter creates, her meta-self chooses which I-self to give dominion: the victim who will express anger or the conqueror who will turn on her favourite music and calm herself down before she reacts. This is how meta-self works when there is no overlap between the I-selves in labels or in definitions (as in the case of example 2 and 5).

When there is overlap between the multiple I-selves, bottom-up processes may also resolve conflicts unconsciously, joining the meta-self's top-down processes. For example, when a mother first joined MADD, she may define herself as a victim of her own anger. But she is not sure whether that definition is most appropriately paired with an angry mother label (example 2) or a MADD supporter label (example 3). Both I-selves hence may exist for a few months as she figures it out. For as long as the two labels share the same definition, the two Iselves and their associated me-selves (the me-self that shares the same label, the same definition or both with the I-selves) may interface with each other in bottom-up and top-down processes. The result of these processes is that these selves may end up with varying degrees of dispositional centrality, situational salience and relevance in determining how the person feels, thinks and acts (Reed et al, 2012; Reed and Forehand, 2016). Meta-self only top-down accelerates or impedes I-self related processes, and then I-selves can top-down accelerate or impede me-self related processes.

\section{How can fundraisers utilize this knowledge to increase fundraising success?}

\section{Me-Self and Giving}


Fundraisers can first map out the most relevant self-transitioning journeys that their potential and existing donors may go through when they make decisions about supporting or remaining with the organization. For example a mother, after losing a child to drunk driving, can unconsciously self-associate with an angry mother identity (Example 1). Because this is a new set of feelings, thoughts, and actions that emerged after her child's death, her me-self probably unconsciously adopts the category label of an angry mother without necessarily her I-self consciously recognizing the clear picture or the association during the few months after the death.

This angry mother me-self can be unconsciously reinforced (i.e. it is strengthened in memory but no other me-selves are strengthened or weakened) or elevated (i.e. it is strengthened in memory and other opposing me-selves weakened) every time she expresses anger and feels comforted afterwards, or unconsciously diluted (i.e. it is weakened but no other me-selves are strengthened) or suppressed (i.e. it is weakened while other me-selves are strengthened) every time expressing anger does not lead to any desirable consequences (Reed and Forehand, 2016; Anderson, et. Al 2008). A vast literature shows that the me-self and its associated unconscious processes can influence behaviour (e.g. giving) and vice versa (McAdams, 2013; Reed et al, 2012).

Tapping into the knowledge on the me-self, fundraisers can grow giving by growing meself's situational salience, dispositional importance and relevance to the decision at hand (Reed \& Foreman, 2016). An advertisement slogan for example can be designed to prime the feelings and the behavioural patterns of the angry mother identity me-self without calling out the category label: "Feeling like screaming in anger? You are not alone! Join 500 other mothers who lost their sons and daughters for a night of sharing this weekend." 
Before a donor consciously associates herself with a relevant category label or consciously defines what that label means to her, we hypothesize that this advertisement will be more effective if it taps into the unconscious looks, feelings (e.g. "Are you feeling angry most of the time?"), thoughts (e.g. "Are you at a loss as to how to cope with losing a child to drunk driving?") and behaviours, without highlighting the category label. This is because doing so may either appear irrelevant, or even false to them. It may put them off because they may consciously think "I am not an angry mother. I am not a victim of my own anger."

Fundraisers should not feel bad about utilizing these techniques in attracting potential donors, especially during the time when some of them are going through probably the worst trauma in their lives. This is because they understand the value their network can offer for these mothers. For example, after attending the first few MADD events, the bottom-up process may allow these mothers to unconsciously associate with a MADD supporter me-self that feels, thinks and behaves more like a conqueror than a victim (this me-self is not marked in Figure 1 due to space constraint). They accomplish this unconscious me-self transition by mimicking what other MADD mothers do. This transition through mimicry can be hugely beneficial for these mothers and increase their psychological well-being (Hill, Summer, \& Burrow, 2014).

\section{I-Self and Giving}

Until when a mother consciously recognizes the difference between the definitions of the two labels, a top-down process from the MADD-mother-conqueror I-self cannot exert any topdown influence into the bottom-up process to elevate the corresponding me-self. Fundraisers' job hence is to detect as soon as possible when that unconscious transition occurs, and help the conscious adoption of the new MADD label and MADD definition as soon as they think 
the new me-self is ready. So that the new I-self can help speed up the helpful transition process.

If fundraisers can map out the typical trajectory and timeline of how these types of selftransitions occur for their donors, they can care for their needs and deepen their connection with the organization more effectively (Shang et al.,2019). For example, fundraising communications can have an outer envelope for a fundraising event invitation to say: "You have done it! You have beaten Anger. Now, let's live in a MADD way! Open the invitation and find out how!"

We hypothesize that this headline should have a higher open rate than any other headlines that make salient only one self in isolation at a time (e.g. Are you angry? Are you a victim of anger? Have you won your battle against anger? Are you living in a MADD way?). This is because it captures the transition process that occurred, not only the starting or the ending point of the transition. It has the potential to make people feel understood and cared for (Nelson, 2019). If these transitions only just occur unconsciously as me-self transitions, we hypothesize, the success of this type of headline can be higher as measured as the facilitation of conscious I-self transitions. If these transitions occur consciously as I-self transitions, we hypothesize, the success of this type of headline can be even higher as measured as response rate to the mailing.

Given that, fundraisers should also be aware that the conscious adoption of a category label (i.e. the adoption of an I-self) does not automatically or immediately expulse the angry mother me-self or terminate any me-self related processes (e.g. reinforcement, elevation, dilution or suppression). It does however have the potential to accelerate or impede processes 
that are only bottom-up. For example, people's MADD-supporter I-Self (defined as a conqueror) can choose to go to MADD gatherings even when their angry-mother me-self (defined as a victim) does not feel like attending.

In doing so, they may meet others and learn how MADD supporters differ from angry mothers. Every time when they feel angry, it is more likely that they know they can conquer it, and it is more likely that they behave differently. This means even though the feeling can still unconsciously trigger their angry-mother me-self as a victim, the thoughts and the behaviours that follow can be more and more often based on the definition of who a MADDsupporter is as a conqueror. If the behaviour is carried out, the MADD-supporter I-self is elevated whereas the angry-mother me-self is suppressed. This elevation and suppression process may be conscious at the time of the person fighting between behavioural options in her own head but can become unconscious as such reflection becomes more automatic and takes less conscious reflection. Neither requires the involvement of the meta-self, because it is a fight between a me-self and an I-self, not two or more I-selves.

The ultimate benefit we think for fundraisers to use fundraising communications to empower their donors with this kind reflection on their self-transition, is not only that they can more sustainably raise funds for their social causes. Rather, they ensure that their donors do so for the right reason by growing the relevance of their causes to their donors' sense of who they are. That is they grow the kind of giving that is motivated by the right I-selves. And it is almost by definition that this kind of giving is more reflective of the personal goals, values and desires (McAdams, 2013; Frankl, 1985). It can increase their sense of competence in mastering their environment (e.g. by consciously identifying more effective coping mechanisms through interacting with other MADD supporters), attaining a higher degree of 
autonomy (i.e. by adopting definitions that are most meaningful to the individual) and having a better sense of personal growth (e.g. as the most meaningful I-selves are consciously reinforced and elevated and the least meaningful me-selves consciously or unconsciously diluted and suppressed (Ryff, 1995, Ryff and Singer, 2008)).

\section{Meta-Self and Giving}

Up to this point of the unconscious adoption of a new MADD-supporter me-self as a conqueror and a conscious adoption of a new MADD-supporter I-self as a conqueror, the meta-self has not exerted any top-down influence other than continuously monitoring whether any new I-selves may have been adopted. This is because any new I-self adopted may pose the potential for conflict that it may be required to manage.

When the meta-self detects that a MADD-supporter I-self defined as a conqueror (example 5) is adopted, it begins to monitor how that may conflict with the MADD-supporter I-self defined as a victim (example 3 ). If the meta-self determines that the conqueror definition allows the mother to experience higher psychological well-being, then it can accelerate the elevation of the MADD-supporter I-self defined as a conqueror (example 5) and the suppression and expulsion of the MADD-supporter I-self defined as a victim (example 3). The meta-self does so by giving dominion to the former whenever possible (e.g. allowing the MADD-supporter I-self to determine whether and how often to attend MADD meetings and how she reacts to minor irritations despite what the angry-mother I-self might feel, think or attempt to behave). 
In order to effectively use this knowledge, fundraisers will have to again assess when typical donors of theirs might be struggling with this kind of choice. Once detected, they can design more targeted digital communications to help them cope better and give more sustainably. For example, fundraisers can relate to the frustration and tiredness that some of the mothers might experience (i.e. their meta-self constantly battling and choosing between two I-selves) by sharing social media advice: "Tired of choosing between winning or losing your battle against anger? MADD supporters have five tips that they can share with you."

In doing so, fundraisers have also taken the concept of "identity relevance" to a more nuanced level. It is no longer only about being relevant to any one self in isolation. Fundraisers can make giving decisions relevant to facilitate the kind of me-self, I-self and meta-self transitions that donors may go through in order to achieve better psychological functioning. When applying the identity relevance principle as an amateur, fundraisers may tap into only one relevant identity at a time (i.e. an angry mother however defined) along one dimension at a time (i.e. object relevance, symbolic relevance, goal relevance, action relevance, or evaluation relevance). But once fundraisers differentiate me-self, I-self and meta-self, identity relevance can be used in a more subtle way to facilitate me-self and I-self transitioning and meta-self functioning.

\section{Not-I-Self, Not-Me-Self and United Self}

What is shared by me-self and I-self is that a self-association between a category label and the self must occur. What remains unaccounted for however is what happens to the category labels that are consciously dis-associated (e.g. I can never be someone who drives the same kind of car as the one that killed my 5-year-old), expulsed (e.g. I am no longer a victim of 
anger) or can never be associated (e.g. I am not my abuser and I am not God) (Example 6 Figure 1)? Can the conscious decision to dis-associate and never-associate allow those category labels to function in ways comparable to those category labels that become an $\mathrm{I} / \mathrm{me}$ self? If so, is there any value to extend the territory of traditional self-schema research into one that includes them?

It is possible that not all such category labels are of relevance. For example, once a mother recognizes that she is no longer a victim of anger, that I-self or me-self is probably best to be deleted from memory, never to surface again. No further bottom-up or top-down processes should be wasted on further processing of that sense of self. But there might be other category labels that even though people know they are singularly unhelpful, they just cannot leave them out of their memory (e.g. I can never be someone who drives that kind of car). But there must be ways that the processing capacity wasted on it can be reduced to minimum.

Finally, there may be dissociation and never-association labels that can help increase psychological well-being. "I am not my abuser" gives the individual confirmation that they have won the most significant battle in how they could define their lives: not becoming their abuser! Is it possible that a confirmation of what they are not is as significant (if not more significant) as a confirmation of who they are (e.g. a good mother)? Is it possible that our understanding of the self should include both how people define who they are and how people set boundaries as to who they are not? Can these two ways of defining the self provide different functional advantages when it comes to growing psychological well-being? If so, what kind of framework would allow us to understand them? What if we introduce the following: 
Not-I-self refers to the selves in which the adoption of category labels is consciously rejected on a temporary or permanent basis.

Not-Me-self refers to the selves in which the adoption of category labels is unconsciously rejected on a temporary or permanent basis.

What makes these category labels part of our sense of self is the reality that these rejected category labels can shape our sense of who we are in ways similar to our I/me-selves. They do so through the same processes like adoption, definition and reinforcement. It may however be necessary to assign a different territory of the self for the existence and the management of these selves. We propose to term that space the United Self.

The United Self is the self that consciously manages the paradox existing between selfassociated and not-self-associated category labels that operate in mutually opposing ways.

Due to space constraints I will not go into detail about whether there is evidence to show that these distinctive components of the self exist or why they must be labelled and defined separately. Nor is there space to explore why we cannot simply call them something that the I/me-self can handle (e.g. the rejected self), or explain why they cannot exist as continuums of the I/me-selves. Details on that can be found in Shang (2019). I will only moot the potential benefits of studying these components of the self for fundraisers.

\section{How can Not-I-Self, Not-Me-Self and United Self help fundraisers?}


It can be helpful for fundraisers to know that I/me-self and Not-I/me-self, although opposites in labels, are not necessarily opposites in definitions. For example, I/me-Self can have one label (e.g. an angry mother) and one definition (e.g. a victim of my anger). The Not-I/me-self however can refer to anything as long as it is not an angry mother defined as a victim of her anger. Not-I/me-self may even have no definition at all. This could be because a definition is not possible (e.g. what does "I am not God" mean?), the attempts to define them are too painful (e.g. what does it mean to be an abuser, so that you can say you are not an abuser?), or it is simply complicated and takes a lot of processing capacity to accomplish (e.g. I am not an angry mother can mean that I am a conqueror of anger, tolerant of anger or some combination of both).

It is my hypothesis that the level of complexity inherent in the definition of the Not-I/me labels is almost always greater than in the definitions of the I/me-labels. Realizing this allows fundraisers to recognize the challenge they may face if they must work with such aspects of self. For example, the Heritage Foundation's mission is to "formulate and promote conservative public policies based on the principles of free enterprise, limited government, individual freedom, traditional American values, and a strong national defence" (The Heritage Foundation, n.d).

Supporters of the Heritage Foundation may define themselves as a republican or as Notliberal or Not-democrat. Those defining themselves as a republican may be more receptive to fundraising messages that are designed to strengthen their conservative values than those defining themselves as a Not-democrat. This is because a republican I-self is more clearly defined and can be precisely elevated by what the Heritage Foundation does. Whereas a Notdemocrat may have multiple meanings (one of which could be that I am simply angry with 
the democrats at the moment). Giving by the Not-democrats may thus be motivated by a more complex array of reasons than giving by republicans. I think fundraising communications can be designed more effectively if fundraisers can detect the most appropriate category label that their supporters accepted as well as rejected, and assess which ones are more important to them and more relevant to the decisions at hand.

Recognizing that people's sense of self may be defined by opposing selves is also important, because people do attempt to create a more harmonious unity in their united self. Here, fundraisers can apply the identity relevance principle to tap into the harmonious existence that unites people's opposing selves. Amnesty International, for example is "the world's leading human rights organisation, campaigning against injustice and inequality everywhere" (Amnesty Internation, n.d). Their supporters can define themselves both as someone who does Not-tolerate-human-rights-abuse and someone who feels for the family and friends of those whose human rights are abused.

The loving-self they have for those who suffer may engender a tender caring tendency in their behaviour, while the No-tolerance-to-abuse-self they have for the abuser may endanger a fighting spirit in guiding their behaviour. The balance between the two may best characterize who a mature Amnesty supporter is. My hypothesis is that fundraising communications can be more effective if fundraisers can characterise all relevant selves that include both their supporters' I-selves and their Not-I-selves rather than only a subset of them.

It is also possible that fundraising messages tapping into how the united-self strikes a harmonious balance in defining who the supporter is and how their holistic sense of who they 
are determines what they do for Amnesty, would be more effective than those that touch on all the separate components in isolation. A balanced fundraising message that acknowledges the two for example could read: "The fight will be long and daunting, but for the sake of those imprisoned we have to say no to human rights abuse until it finally comes to an end." The first half of this message touches the loving-self and the second half touches the Notolerance self. And the harmony the united self drives is one in which Amnesty supporters fight for as long as necessary to care for (and express their love for) the abused.

\section{CONCLUSION}

In this chapter, I explained how the $\mathrm{I} /$ me selves and meta-self can help raise more sustainable charitable income and grow donors' psychological well-being. I also mooted the possibility of exploring the Not-I/me selves and the united self and hypothesized what their potential value may be in reaching the same goals. The successful application of much what I suggest in this chapter is contingent on fundraisers' ability to understand their donors in a deep level and in real time. Without the digital revolution, these ideas would be difficult to operationalize and implement, but as organizations increasingly interact with donors in realtime, the ability to hyper-personalize communication is now a reality. Nonprofits now have a significant and meaningful opportunity to enhance the quality of the donor experience and grow both individual giving and personal wellbeing as a consequence. 


\section{References}

Amnesty International, n.d. The Description. Retrieved from http://www.amnesty.org.uk Anderson, J. R., Bothell, D., Byrne, M. D., Douglass, S., Lebiere, C., \& Qin, Y . (2004). An integrated theory of the mind. Psychological Review 111, (4). 1036-1060.

Andrews, P. W., \& Thomson Jr, J. A. (2009). The bright side of being blue: depression as an adaptation for analyzing complex problems. Psychological review, 116(3), 620.

Bahl, Shalini and Milne, George R. (2010). Talking to Ourselves: A Dialogical Exploration of Consumption Experiences. Journal of Consumer Research, 37, 176-195.

Beck, A. T., Rush, A. J., Shaw, B. F., \& Emery, G. (1979). Cognitive therapy of depression. New York: Guilford Press.

Belk, Russell W. (1988). Possessions and the Extended Self. Journal of Consumer Research, $15,139-168$.

Boski, P. (1991). Remaining a Pole or Becoming a Canadian: National Self-Identity among Polish Immigrants to Canada. Journal of Applied Social Psychology, 21, 41-77.

Brewer, M. B., \& Gardner, W. (1996). Who is this" We"? Levels of collective identity and self representations. Journal of Personality and Social Psychology, 71, 83-93.

Brewer, M. B., \& Pierce, K. P. (2005). Social identity complexity and outgroup tolerance. Personality and Social Psychology Bulletin, 31, 428-437.

Deaux, K. Reid, A., Mizrahi, K., \& Ethier, K. (1995). Parameters of social identity. Journal of Personality and Social Psychology, 68, 280-291.

Dong, L. \& Tian, K. (2009). The use of western brands in asserting Chinese national identity. Journal of Consumer Research, 36, 504-523.

Epp. A. M. \& Price, L. L. (2008). Family identity: A framework of identity interplay in consumption practice. Journal of Consumer Research, 35, 50-70.

Erikson, E. (1959). Identity and the life cycle. Psychological Issues, 1, 18-164.

Erikson, E., \& Erikson, J. M. (1998). The life cycle completed (extended version). London: WW Norton \& Company.

Frankl, Vicktor E. (1985). Man's search for meaning. Boston: Beacon Press.

Giving USA (2016), Giving USA 2016: The Annual Report on Philanthropy for the Year 2015, Glenview, IL: American Association of Fundraising Counsel.

Guo, Jen; Klevan Miriam, Klevan and McAdams, Dan P. (2016). Personality Traits, Ego Development, and the Redemptive Self. Personality and Social Psychology Bulletin, 42(1), 1551-1563.

Heritage Foundation, n.d. The mission. Retrieved from https://www.heritage.org/aboutheritage/mission

Higgins, Tory E. (1987). Self-Discreancy: A Theory Relating Self and Affect. Psychological Review. 94(3), 319-340.

Hill, Patrick L., Rachel Sumner, and Anthony L. Burrow. "Understanding the pathways to purpose: Examining personality and well-being correlates across adulthood." The Journal of Positive Psychology 9, no. 3 (2014): 227-234.

Johnson Joel T.; Robinson Michael D. and Mitchell, Emilie B. (2004), Inferences About the Authentic Self: When Do Actions Say More Than Mental States? Journal of Personality and Social Psychology, 87(5), 615-630.

Kong, DeJie (2018). Organizational Identity and Charitable Giving, Dissertation from the University of Plymouth.

Kühnen, Ulrich; Hannover, Bettina and Schubert, Benjamin (2001). The Semantic-Procedural Interface Model of the Self: The Role of Self-Knowledge for Context-Dependent Versus Context-Independent Modes of Thinking. Journal of Personality and Social Psychology, 80(3), 397-409. 
MADD, n.d. The mission. Retrieved from https://www.madd.org/

McAdams, Dan P. (2013). The Psychological Self as Actor, Agent, and Author, Perspectives on Psychological Science, 8(3), 272-295.

McConnell, A. R. (2010). The multiple self-aspects framework: Self-concept representation and its implications. Personality and Social Psychology Review, 15, 3-27

Nelson, Deanna (2018). Moral Identity, Self-Disclosure and Major Gift Fundraising, Dissertation from the University of Plymouth.

Oyserman, D. (2009). Identity-based motivation: Implications for action-readiness, procedural readiness, and consumer behaviour. Journal of Consumer Psychology, 19, 250-260.

Reed, Americus. "Activating the self-importance of consumer selves: Exploring identity salience effects on judgments." Journal of consumer research 31, no. 2 (2004): 286295.

Reed II, Americus, and Mark R. Forehand. "The ebb and flow of consumer identities: the role of memory, emotions and threats." Current Opinion in Psychology 10 (2016): 94-100.

Reed, Americus, Mark R. Forehand; Puntoni, Stefano and Warlop, Luk (2012). Identitybased consumer behaviour, International Journal of Research in Marketing, 310-321.

Ryff, C. D., \& Keyes, C. L. M. (1995). The structure of psychological well-being revisited. Journal of Personality and Social Psychology, 69, 719-727.

Ryff, C. D., \& Singer, B. H. (2008). Know thyself and become what you are: A eudaimonic approach to psychological well-being. In The Exploration of Happiness (pp. 97-116). Netherlands: Springer.

Sargeant, A., \& Jay, E. (2014). Fundraising management, analysis, planning and practice. London: Routledge.

Schimel, J. Arndt, J., Banko, Pyszcynski, T. \& Greenberg, J. (2001). Being accepted for who we are: Evidenced that social validation of the intrinsic self reduces general defensiveness. Journal of Personality and Social Psychology, 80, 35-52.

Schlegel, Rebecca J., Hicks, Joshua A., Arndt, Jamie and King, Laura A. (2009). Thine Own Self: True Self-Concept Accessibility and Meaning in Life, Journal of Personality and Social Psychology, 96(2), 473-490.

Schlegel, Rebecca J.; Hicks, Joshua A.; King, Laura A. and Arndt, Jamie (2011). Feeling Like You Know Who You Are: Perceived True Self-Knowledge and Meaning in Life. Personality and Social Psychology Bulletin, 37(6), 745-756.

Sargeant, Adrian (2018). About Loyalty, Working Paper University of Plymouth.

Shang, Jen (2018). The Theory of United Self, Working Paper University of Plymouth.

Shang, Jen and Sargeant, Adrian (2018). Christian Identity and Charitable Giving, Working Paper University of Plymouth.

Shang, Jen; Reed, Americus; Sargeant, Adrian and Carpenter, Kathryn (2018). Moral Identity Discrepancy, Gender and Charitable Giving, Working Paper University of Plymouth.

Swann Jr, W. B., Jetten, J., Gómez, A., Whitehouse, H., \& Bastian, B. (2012). When group membership gets personal: a theory of identity fusion. Psychological Review, 119, 441456.

United Nations. (2015). Resolution adopted by the General Assembly on 25th September 2015; 70/1 Transforming our world: the 2030 agenda for sustainable development. Retrieved from https://sustainabledevelopment.un.org/post2015/transformingourworld.

Vago, David R., and Silbersweig AMD David. "Self-awareness, self-regulation, and selftranscendence (S-ART): a framework for understanding the neurobiological mechanisms of mindfulness." Frontiers in human neuroscience 6 (2012): 296. 
Voyer, Benjamin G. and Franks, Bradley (2014). Toward a Better Understanding of SelfConstrual Theory: An Agency View of the Processes of Self-Construal. Review of General Psychology, 18(20), 101-114. 


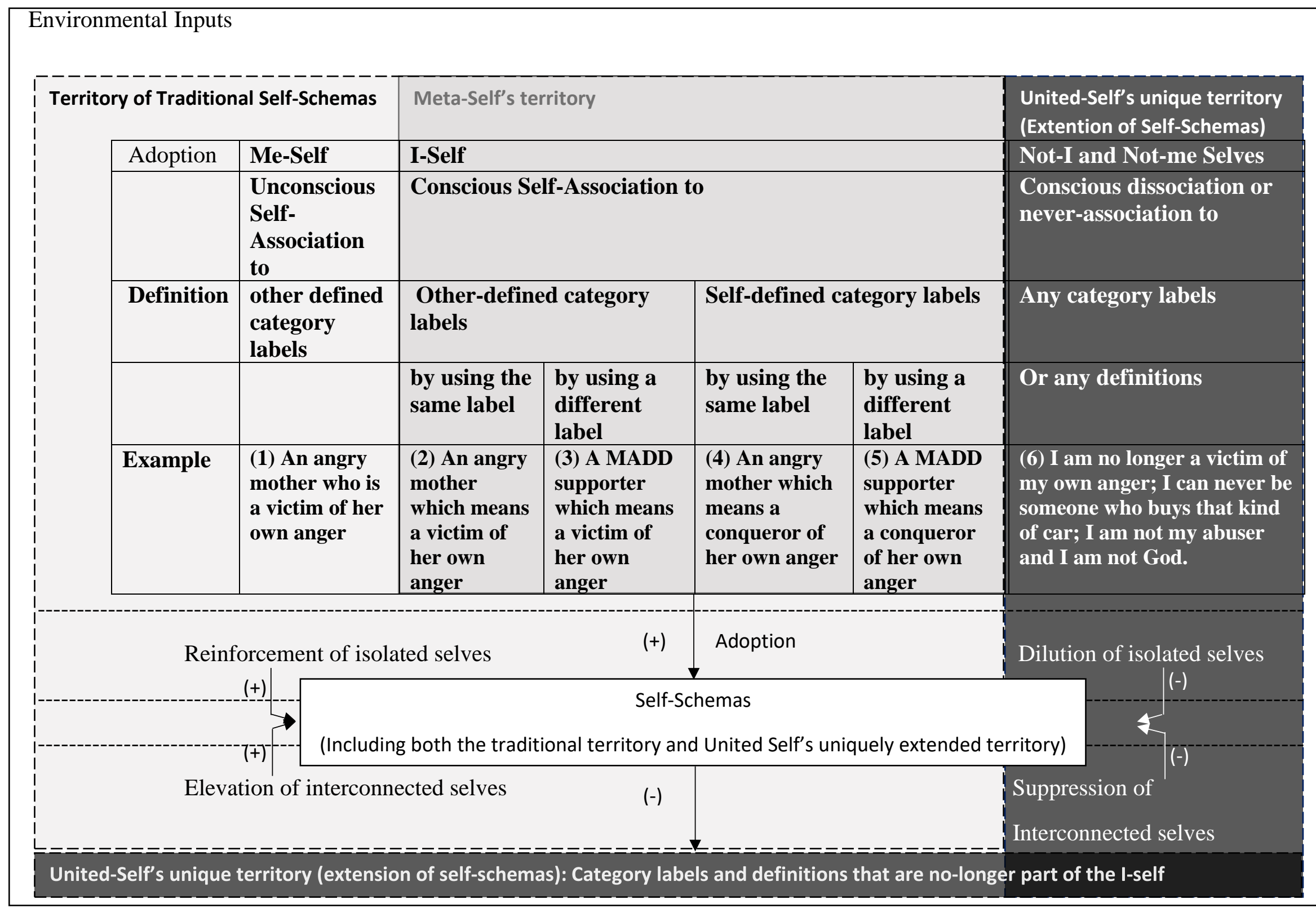

